\title{
An Assessment of Heliostat Control System Methods
}

Jim Pearson (John Brown University)

Bing Chen (University of Nebraska)
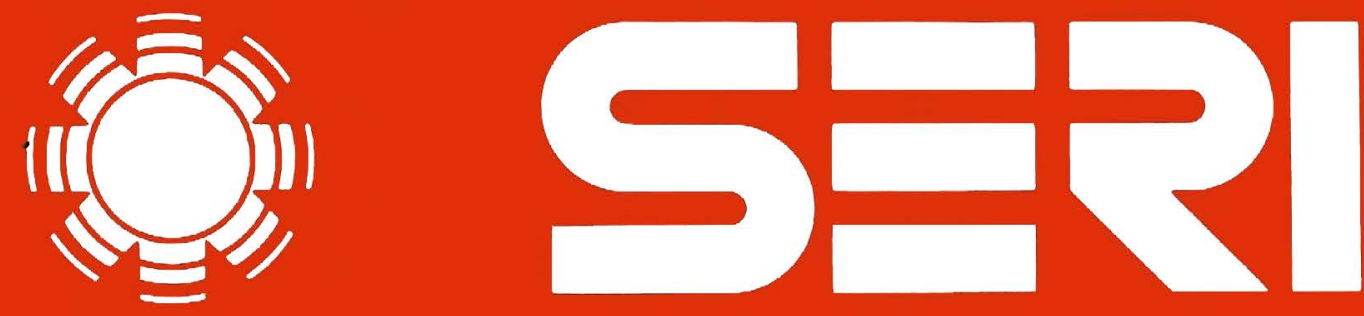

Solar Energy Research Institute A Division of Midwest Research Institute

1617 Cole Boulevard

Golden, Colorado 80401-3393

Operated for the

U.S. Department of Energy

under Contract No DE-AC02-83CH10093 


\section{NOTICE}

This report was prepared as an account of work sponsored by the United States Government. Neither the United States nor the United States Department of Energy, nor any of their employees, nor any of their contractors, subcontractors, or their employees, makes any warranty, expressed or implied, or assumes any legal liability or responsibility for the accuracy, completeness or usefulness of any information, apparatus, product or process disclosed, or represents that its use would not infringe privately owned rights.

\section{Printed in the United States of America \\ Available from:}

National Technical Information Service

U.S. Department of Commerce

5285 Port Royal Road

Springfield, VA 22161

Price: Microfiche A01

Printed Copy $\mathrm{AOO}$

Codes are used for pricing all publications. The code is determined by the number of pages in the publication. Information pertaining to the pricing codes can be found in the current issue of the following publications. which are generally available in most libraries: Energy Research Abstracts, (ERA): Government Reports Announcements and Index (GRA and I); Scientific and Technical Abstract Reports (STAR); and publication, NTIS-PR-360 available from NTIS at the above address. 
SERI/SP-253-2390

UC Category: 62

DE86004416

\section{An Assessment of Heliostat Control System Methods}

Jim Pearson (John Brown University)

Bing Chen (University of Nebraska)

January 1986

Prepared under Task No. 5102.31

FTP No. 463

Solar Energy Research Institute

A Division of Midwest Research Institute

1617 Cole Boulevard

Golden, Colorado 80401

Prepared for the

U.S. Department of Energy

Contract No. DE-AC02-83CH10093 


\section{PREFACE}

The research and development described in this document was conducted within the U.S. Department of Energy's Solar Thermal Technology Program. The goal of this program is to advance the engineering and scientific understanding of solar thermal technology and to establish the technology base from which private industry can develop solar thermal power production options for introduction into the competitive energy market.

Solar thermal technology concentrates the solar flux using tracking mirrors or lenses onto a receiver where the solar energy is absorbed as heat and converted into electricity or incorporated into products as process heat. The two primary solar thermal technologies, central receivers and distributed receivers, employ various point and linefocus optics to concentrate sunlight. Current central receiver systems use fields of heliostats (two-axis tracking mirrors) to focus the sun's radiant energy onto a single, tower-mounted receiver. Point focus concentrators up to 17 meters in diameter track the sun in two axes and use parabolic dish mirrors or Fresnel lenses to focus radiant energy onto a receiver. Troughs and bowls are line-focus tracking reflectors that concentrate sunlight onto receiver tubes along their focal lines. Concentrating collector modules can be used alone or in a multimodule system. The concentrated radiant energy absorbed by the solar thermal receiver is transported to the conversion process by a circulating working fluid. Receiver temperatures range from $100^{\circ} \mathrm{C}$ in low-temperature troughs to over $1500^{\circ} \mathrm{C}$ in dish and central receiver systems.

The Solar Thermal Technology Program is directing efforts to advance and improve each system concept through solar thermal materials, components, and subsystems research and development and by testing and evaluation. These efforts are carried out with the technical direction of DOE and its network of national laboratories that works with private industry. Together they have established a comprehensive, goal-directed program to improve performance and provide technically proven options for eventual incorporation into the Nation's energy supply.

To successfully contribute to an adequate energy supply at reasonable cost, solar thermal energy must be economically competitive with a variety of other energy sources. The Solar Thermal Program has developed components and system-level performance targets as quantitative program goals. These targets are used in planning research and development activities, measuring progress, assessing alternative technology options, and developing optimal components. These targets will be pursued vigorously to ensure a successful program.

This work has evolved out of and in support of the innovative concentrator effort at SERI. The innovative concentrator work, supported by the Division of Solar Thermal Technology, U.S. Department of Energy (DOE), is to reduce overall collector costs including the control and communication elements that require significant cost/ performance improvements. The support of the DOE/ASEE Summer Faculty Research Program during the summers of 1982 and 1983 is gratefully acknowledged, for without it this effort would not have been undertaken.

The authors would like to thank the following individuals who have given them significant information and/or advice during their research: L. M. Murphy and J. Thorton of SERI; R. Gee and C. Vineyard (formerly of SERI); D. Tanner and R. Alvis of Sandia National Laboratories; D. Elliott, D. Christian, and M. Slominski of DOE; R. Beheti of GE; 
SP -2390

SEPI 綪

B. Scott of Motorola; M. Lee and C. Schmaltz of National Semiconductor; T. Williamson of Intel; R. Chepaner of Plassey Semiconductor; P. Cross of Spectra Diode Laboratories; and W. Hart and colleagues of Martin Marietta Corporation.
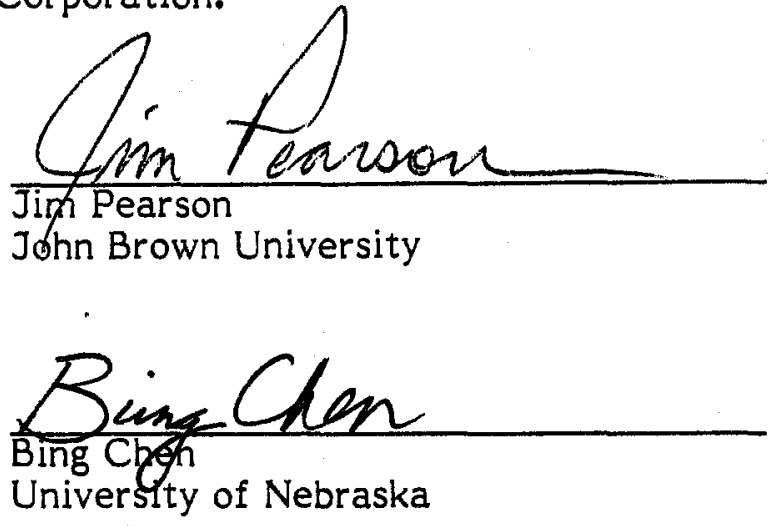

Approved for

SOLAR ENERGY RESEARCH INSTITUTE
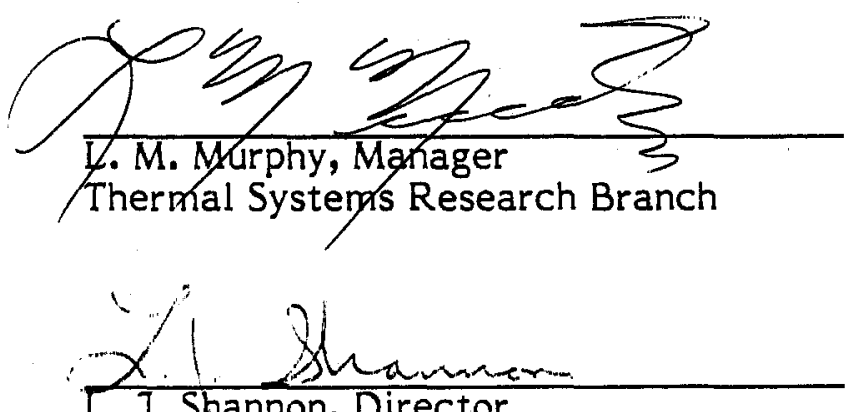

T. J. Shannon, Director

Solar Heat Research Division

iv 


\section{SUMMARY}

\section{Objective}

The objective of this report is to identify and assess alternative control and communication subelements for heliostats that have the potential to reach $\$ 15 / \mathrm{m}^{2}$ of heliostat mirror area. The cost goal of $\$ 15 / \mathrm{m}^{2}$ compares with the $\$ 50 / \mathrm{m}^{2}$ for communication and control at the Solar One facility in Barstow, Calif., and with estimates of about $\$ 25 / \mathrm{m}^{2}$ for second-generation systems. To achieve the cost goal the primary objectives are (1) to identify and (2) to assess the technical feasibility of alternative approaches to heliostat communication and control systems.

\section{Discussion}

Completed in 1982, the solar thermal power plant at Barstow, Calif., is a joint effort of DOE and Southern California Edison Company. With a total of 1818 heliostats, each of which has $40 \mathrm{~m}^{2}$ of reflector surface, the Solar One facility is designed to produce $10 \mathrm{MW} \mathrm{e}$. The installed heliostat cost per square meter of heliostat surface area is $\$ 375$; of this total, $\$ 50$ are for heliostat communication, control, and heliostat actuator. The target goal for second-generation heliostats (communication, control, and activator elements) is $\$ 25 / \mathrm{m}^{2}$. In this study we were able to demonstrate the potential to reduce the cost of the heliostat communication-control system to $\$ 9 / \mathrm{m}^{2}$.

At the Barstow facility communication between the central computer and the heliostats is via buried cable; i.e., from the central computer to a field computer and then to the heliostat computer. Sun-vector information computed by the central computer and mode-change instructions are transmitted to each of the heliostat field computers. The data are then distributed to each heliostat microcomputer via buried cable. The azimuth and elevation gimbal angles are calculated. The local heliostat computer then controls the azimuth and elevation actuators. Since the actuators are dc motors, information concerning their actual position must be fed back to the heliostat computer to compare the actual position with the desired position. Status information only flows from the heliostat field back to the central computer.

To reduce heliostat control and communication cost, this study considers a number of alternative methods. These promising methods emerged as a result of new technological and cost breakthroughs since the development of Solar One and the subsequent secondgeneration development effort. The two fundamental areas that are the major concentration of this study are: (1) alternatives to the present buried, shielded signal-cable communication line and (2) an upgrading of the functions and control responsibilities of each heliostat microcomputer.

The four alternatives to buried, shielded-cable communication systems that we considered are fiber optics, carrier current, radio frequency (RF), and optical air links using a laser or light-emitting diodes. The first two communication alternatives, fiber optics and carrier current, still involve buried cable (either fiber optic cable or the existing power cable, respectively), whereas the last two alternatives, RF and optical air links, do not. All four of the alternative communication systems eliminate the problem of electromagnetic interference (EMI) that exists with the type of dedicated signal cabling at Solar One in Barstow, Calif. EMI problems typically occur as a result of lightning strikes at, or adjacent to, the heliostat field. Except for the carrier current option, the 
data transmission rate and accuracy of the communication alternatives either equal or exceed the buried, shielded signal-cable approach. Further, except for the optical air link, the alternative communication systems can relay enhanced information concerning each heliostat's status back to the central computer.

Solar One employs dedicated, buried signal cabling for communication. Some problems occurred with electromagnetic interference caused by lightning strikes adjacent to the site. As an alternative, Martin Marietta Corporation proposed fiber optics for the second-generation solar thermal plant. Communication from the central computer to the heliostat computer is via a buried light-carrying cable. A much higher data rate and freedom from EMI, as well as a lower cost of $\$ 25 / \mathrm{m}^{2}$ of heliostat surface, make fiber optics an attractive alternative to buried cable.

A second alternative for communication, the carrier-current link, takes advantage of the buried power lines that must go to each heliostat. The information from the central computer is impressed upon a carrier wave that rides upon the $60-\mathrm{Hz}$ (cycles per second) power signal. This system is somewhat vulnerable to EMI and the highest data rate available at present is 4 kbaud (compared to the 10-kbaud rate for dedicated cabling). The power transformers that may be used in the power distribution system in the heliostat field also create problems when transmitting the data signal. However, the estimated cost of $\$ 10 / \mathrm{m}^{2}$ for this concept is very promising.

The RF and optical air link are the last two communication system alternatives and have attractive estimated costs of $\$ 9 / \mathrm{m}^{2}$ and $\$ 13 / \mathrm{m}^{2}$, respectively. Both systems transmit through the air between central receiver and heliostat and both eliminate EMI problems. The RF scheme allows transmission and reception at $10 \mathrm{kbaud}$, which is equal to that of dedicated cable. The recent advent of inexpensive electronics hardware and the high-speed, two-way transmission between central computer and heliostat make the RF technique particularly attractive. Its incorporation into a power facility poses few serious technological problems. Optical air links, on the other hand, would require more design and testing. The estimated cost of $\$ 13 / \mathrm{m}^{2}$ is within the original $\$ 15 / \mathrm{m}^{2}$ design goal. The cost, however, reflects a one-way (simplex) communication scheme only; the cost for two-way (duplex) communication between heliostat and central computer is too prohibitive to be considered economically feasible at this time. In the simplex mode, an optical transmitter (laser or LED) is mounted on the receiver tower. There are optical detectors at each heliostat. The optical transmitter communicates to the heliostat field via a wide-angle aperture at the central tower or through computer-driven prisms that pinpoint the exact heliostat position desired.

Five different control strategies are discussed in some detail. In essence two primary stages are at the central computer and at the heliostat. Each subsystem may be open loop (no feedback of information) or closed loop (feedback). Solar One exemplifies an open-loop central computer and a closed-loop heliostat arrangement. Mode change instructions and sun vector calculations are sent from the central computer to the heliostat field and only heliostat status information is fed back. The heliostats at Solar One, since they have dc-driven actuators, require a closed-loop feedback system so that the on-board heliostat computers can accurately point the heliostat to the receiver.

We found that enhancing the computing functions of each heliostat computer to perform sun vector calculations can relieve the central computer of that responsibility. Each heliostat computer can also use an error model estimation algorithm for self-calibration and possibly an adaptive controller to enhance the interrogation potential at the central computer. This approach is considerably different from the one used at Solar One where 
the heliostat computers receive the sun vector from the central computer through the intermediary field computers. The heliostat computer then calculates the heliostat pointing vector. If the previous heliostat pointing vector changes, the heliostat computer causes the elevation and azimuth drives to repoint the heliostat. We recommend the upgrading of computing functions and responsibilities by the helios tat computers because of recent significant price reductions and greater available computing capability.

\section{Conclusion}

The analysis to date shows that the control and communication approach with the greatest promise for success employs the RF or carrier current communication line techniques and an upgraded heliostat computer for control. Both RF and carrier-current methods incorporate established and successful technologies. In addition to a lower cost (when compared with second-generation fiber optics), RF and carrier-current lines provide for two-way communication between heliostat and central computer. An RF communication link with appropriate modulation and coding would also eliminate EMI noise problems. With the price of microcomputers plummeting and the development of special-purpose microcomputers such as the Intel 8051 , which is specifically dedicated to control functions, the authors feel that serious effort should be given to enhancing the responsibility of the heliostat computer in the field. Knowledge of time of day from the central computer would allow the heliostat computer to calculate the sun vector, which when added to the tower vector would give the heliostat inertial pointing vector. An on-board error model developed during an initial calibration phase would account for errors related to heliostat fabrication and installation at the site. A self-tuning adaptive controller could be developed to handle random loads and disturbances such as the effects of wind loading. In the future we plan to interface and attach an enhanced heliostat computer to a third-generation heliostat and to use the RF or carrier-current communication link. Successful testing would demonstrate the technical feasibility of the alternative communication-control system. The target goal of $\$ 15 / \mathrm{m}^{2}$ (compared to $\$ 50 / \mathrm{m}^{2}$ at Solar One) for the communication-control and actuator subystem is realizable based on the cost analysis described in this report. 


\section{TABLE OF CONTENTS}

Page

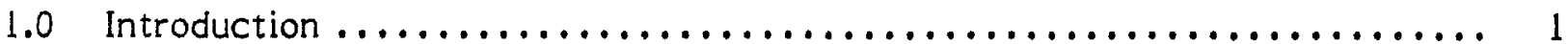

2.0 A Summary of Recent Research $\ldots \ldots \ldots \ldots \ldots \ldots \ldots \ldots \ldots \ldots \ldots \ldots \ldots \ldots \ldots$

3.0 The Design Problem $\ldots \ldots \ldots \ldots \ldots \ldots \ldots \ldots \ldots \ldots \ldots \ldots \ldots \ldots \ldots \ldots \ldots$

4.0 Control Methods $\ldots \ldots \ldots \ldots \ldots \ldots \ldots \ldots \ldots \ldots \ldots \ldots \ldots \ldots \ldots \ldots \ldots \ldots \ldots$

4.1 Open-Loop Central Computer Control with Closed-Loop

Heliostat Computer Control ......................... 8

4.2 Open-Loop Central Computer Control with Open-Loop Heliostat Computer Control .......................... 8

4.3 Closed-Loop Central Computer Control with Back Gazing ........... 9

4.4 Open-Loop Minimal Central Computer Control with Open-Loop Heliostat Computer Control ..................... 10

4.5 Open-Loop Minimal Central Computer Control with Closed-Loop Heliostat Control ........................ 10

5.0 Communication Methods $\ldots \ldots \ldots \ldots \ldots \ldots \ldots \ldots \ldots \ldots \ldots \ldots \ldots \ldots \ldots$

5.1 Dedicated Cabling $\ldots \ldots \ldots \ldots \ldots \ldots \ldots \ldots \ldots \ldots \ldots \ldots \ldots \ldots \ldots \ldots \ldots \ldots$

5.2 Fiber Optics Link ............................... 11

5.3 Radio Frequency Link ............................ 11

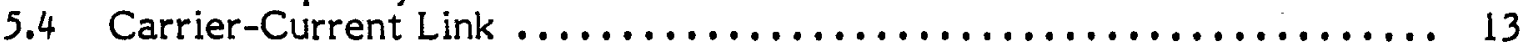

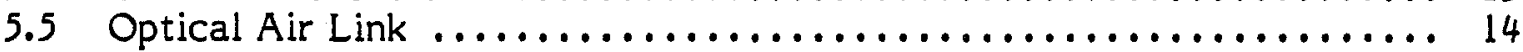

6.0 Actuator, Calibration Method, and Clock .................... 16

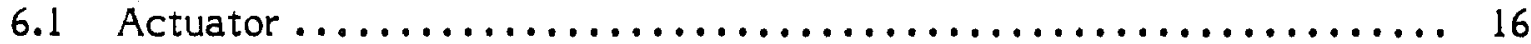

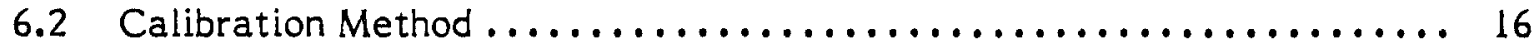

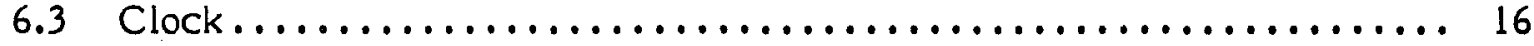

7.0 Heliostat Controller Selection $\ldots \ldots \ldots \ldots \ldots \ldots \ldots \ldots \ldots \ldots \ldots \ldots \ldots \ldots$

7.1 Control Method Selection .......................... 17

7.2 Communication Method Selection $\ldots \ldots \ldots \ldots \ldots \ldots \ldots \ldots \ldots \ldots \ldots \ldots$

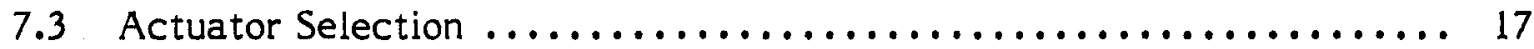

7.4 Calibration Method Selection .......................... 19

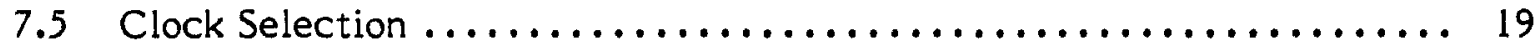

7.6 Selection Summary .................................. 19

8.0 Proposed Research and Expected Results ..................... 23

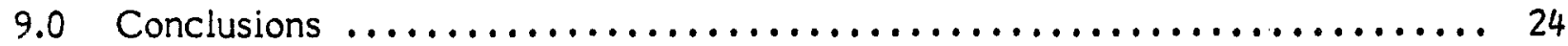

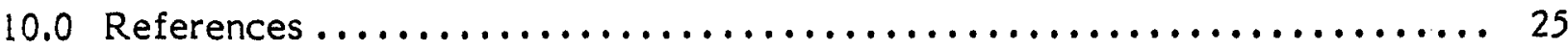


TABLE OF CONTENTS (Concluded)

\begin{abstract}
Page
Appendix A Self-Calibrating Controllers $\ldots \ldots \ldots \ldots \ldots \ldots \ldots \ldots \ldots \ldots \ldots \ldots$

Appendix B Intel 8051 Microcontroller ......................... 27

Appendix C Adaptive Self-Tuning .............................. 39
\end{abstract}




\section{LIST OF FIGURES}

3-1 Design Problem ................................... 5

4-1 Control System Alternatives ........................... 7

7-1 Proposed Heliostat Control System--Open-Loop Minimal

Central Computer with Open-Loop Heliostat Computer Control . . . . . . . . 18

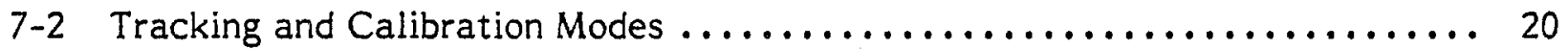

\section{LIST OF TABLES}

5-1 Heliostat Communication Systems $\ldots \ldots \ldots \ldots \ldots \ldots \ldots \ldots \ldots \ldots \ldots \ldots \ldots$

5-2 Solar One Control System Cost .......................... 13

5-3 Second-Generation Control System Cost .................... 13

5-4 RF Control System Cost $\ldots \ldots \ldots \ldots \ldots \ldots \ldots \ldots \ldots \ldots \ldots \ldots \ldots \ldots \ldots \ldots$

5-5 Carrier-Current Control System Cost $\ldots \ldots \ldots \ldots \ldots \ldots \ldots \ldots \ldots \ldots \ldots \ldots \ldots$

5-6 Optical Air Link Control System Cost .................... 15 


\section{SECTION 1.0}

\section{INTRODUCTION}

The first commercially operated, solar thermal central receiver power plant in the United States (Solar One) is now on-line at Barstow, Calif. The system is currently functioning quite well and has already fulfilled many of its objectives, having demonstrated technical and operational feasibility. Cost and performance feasibility are yet to be demonstrated and will depend not only on the performance results now being generated but also on the ability of the DOE technical community to further reduce collector and other subsystem costs to anticipated, significantly lower levels.

For solar thermal systems to be competitive with a wide range of conventional fuels in many areas of the country, the DOE cost goal committee has developed a target of $\$ 100 / \mathrm{m}^{2}$ for the entire installed solar thermal plant [1]. Of this amount, about half or $\$ 50 / \mathrm{m}^{2}$ would apply to heliostat array costs. The heliostat array cost for Solar One in Barstow, Calif., was $\$ 375 / \mathrm{m}^{2}$ and the projected cost for the second-generation heliostats* is $\$ 130 / \mathrm{m}^{2 * *}$ (which includes the power cabling [2]). Both costs are much higher than the $\$ 50 / \mathrm{m}^{2}$ goal. Heliostat array costs are further subdivided into the cost of the heliostats and the communication-control actuator system. For second-generation heliostat systems, the projected cost of the communication-control system including actuators is $\$ 25 / \mathrm{m}^{2}[3]$.

When this study was initiated, the primary goal was to identify alternative approaches that would have the potential to reduce the cost of the communication-control system (including actuators) to $\$ 15 / \mathrm{m}^{2}$. As the study progressed, we identified several alternative methods that lead to designs that can potentially achieve costs in the $\$ 9-\$ 13 / \mathrm{m}^{2}$ range for particular control and communication elements.

* Design modification following the Solar One prototype.

**The corresponding estimated cost for the enhanced second-generation $100-\mathrm{m}^{2}$ designs is about $\$ 104 / \mathrm{m}^{2}$. 


\section{SECTION 2.0}

\section{A SUMMARY OF RECENT RESEARCH}

Subsequent to the Solar One development program, research on innovative control and communication schemes has been carried out on a moderate level. The research includes efforts on radio frequency (Martin Marietta Corporation) and power-cable carriercurrent (Sandia National Laboratories, Albuquerque [SNLA]) approaches for communication, and the distributed intelligence-computing approach to control. Radio frequency (RF) data linking was considered early in the planning of Solar One. It was rejected, after a very cursory review, on the basis of a cost and performance evaluation. The decision was appropriate since supervisory control transmitter-receivers cost more than $\$ 1000$ at the time (1975). Now (1984) integrated-circuit communication elements only cost about $\$ 50$, are considerably smaller, and have an enhanced noise rejection performance. Recent research on the RF data-link approach can be divided into four periods: (1) initial primary studies at SERI during the summer of 1982 by two visiting professors (participants in the DOE/ASEE Summer Faculty Research Program); (2) subsequent academic and applications-oriented studies by the authors and their students at their respective universities during the academic year of 1982-83; (3) research on data links and controllers by the authors at SERI during the summer of 1983; and (4) continued studies on the data link and the controller by the authors and their students during the academic year of 1983-84.

SNLA developed a power-cable, carrier-current control system for trough collectors in 1981 [4]. In the summer of 1983, National Semiconductor made available a transceiver integrated circuit (IC) for carrier-current data links [5]. The unit cost is approximately $\$ 12$, which is greatly reduced from the cost of only a few years ago $(\$ 600-\$ 800)$.* $A$ carrier-current system incorporating this component is now being evaluated.

Solar One involves a distributed control system with three levels of control: a central computer, a field microcomputer controlling 14-32 heliostats, and the heliostat microcomputer. The field microcomputer receives the sun vector calculations from the central computer and distributes them to the heliostat microcomputer, which calculates the appropriate gimbal angles and activates the dc motors. The cost and performance of microcomputer technologies have advanced so rapidly since completion of Solar One and the second-generation heliostat development programs that it now seems appropriate to place more computing capability at the heliostat and to eliminate the field microcomputers. During the summer of 1982, the two visiting professors studied the possibilities of (1) doing the sun vector calculation at each heliostat and (2) using an error-model estimation algorithm [6] for self-calibration (see Appendix A). Further work has been done to select a microcontroller that would have an advantage over the existing microcomputer in terms of real-time processing capability, high-speed execution, fast context change, and facility for decision making (see Appendix B). The research indicates that such a microcontroller will make it possible to realize on-line system parameter identification and self-tuning control (a low-level adaptive control) (see Appendix C) [7].

One of the major potential problems anticipated with the use of an RF data link is multipath propagation in a field with many metal surfaces. Martin Marietta performed some

* Most cost estimates for this study were developed in the summer of 1982 by Conrad Vineyard who was then a SERI employee. 
experiments at Solar One in January of 1984. These experiments were performed with the transmitting antenna on the ground and on the tower. While ground transmission was unsuccessful, tower transmission was successful. Some areas in the field had reduced power levels; however, it was concluded that multipath problems would not prevent effective communication if RF transmission was from a tower. 


\section{SECTION 3.0}

\section{THE DESIGN PROBLEM}

To develop low-cost alternatives to control and communication of heliostats, we formulated a design problem that included basic operational and performance requirements. Our aim was to concentrate on rigidly meeting these basic requirements but not necessarily meeting other desirable, but expendable, requirements.

Figure 3-1 describes the major assumptions of the design problem. The problem is to design a means of communicating mode change and time-of-day information from a central computer to up to 10,000 heliostats, locally computing the appropriate azimuth and elevation angles at the specific heliostat location, actuating the heliostat to the computed position with a prescribed pointing and tracking accuracy, and communicating the present status of the heliostat from the heliostat to the central computer. The operational modes that must be possible at the heliostat and assumed for this study are as follows:

- Wake-up mode--heliostat moves from a stow position to a sun-tracking position

- Maintenance mode--heliostat is available for manual operation and mechanical and electronic maintenance

- Stow mode--heliostat is in a storm-protection position

- Tracking mode--heliostat tracks the sun

- Calibration mode--heliostat error vector is able to be calibrated.

The design criteria are to (1) achieve a minimum 1.5-mrad pointing accuracy, (2) achieve a minimum 2.0 -mrad tracking accuracy, (3) update the heliostat position every 4 seconds, and (4) be able to stow the heliostat within 5 minutes. Other major design constraints are that (1) the system must be able to control up to 10,000 heliostats and (2) the cost must not exceed $\$ 15 / \mathrm{m}^{2}$ for the communication-control actuator subsystem.

The heliostat tracking control system requires (1) a control method, (2) a communication method, (3) azimuth and elevation actuators, (4) a calibration method, and (5) a time-ofday clock.

Various candidate control-and-communication approaches that can potentially satisfy these requirements are discussed in the next sections.

In order of importance, the hierarchy of decision criteria and drivers in the selection process are (1) cost, (2) tracking accuracy, (3) pointing accuracy, (4) type of communication (simplex or full duplex), (5) updating rate, (6) interrogation rate, (7) serviceability, and (8) flexibility. 


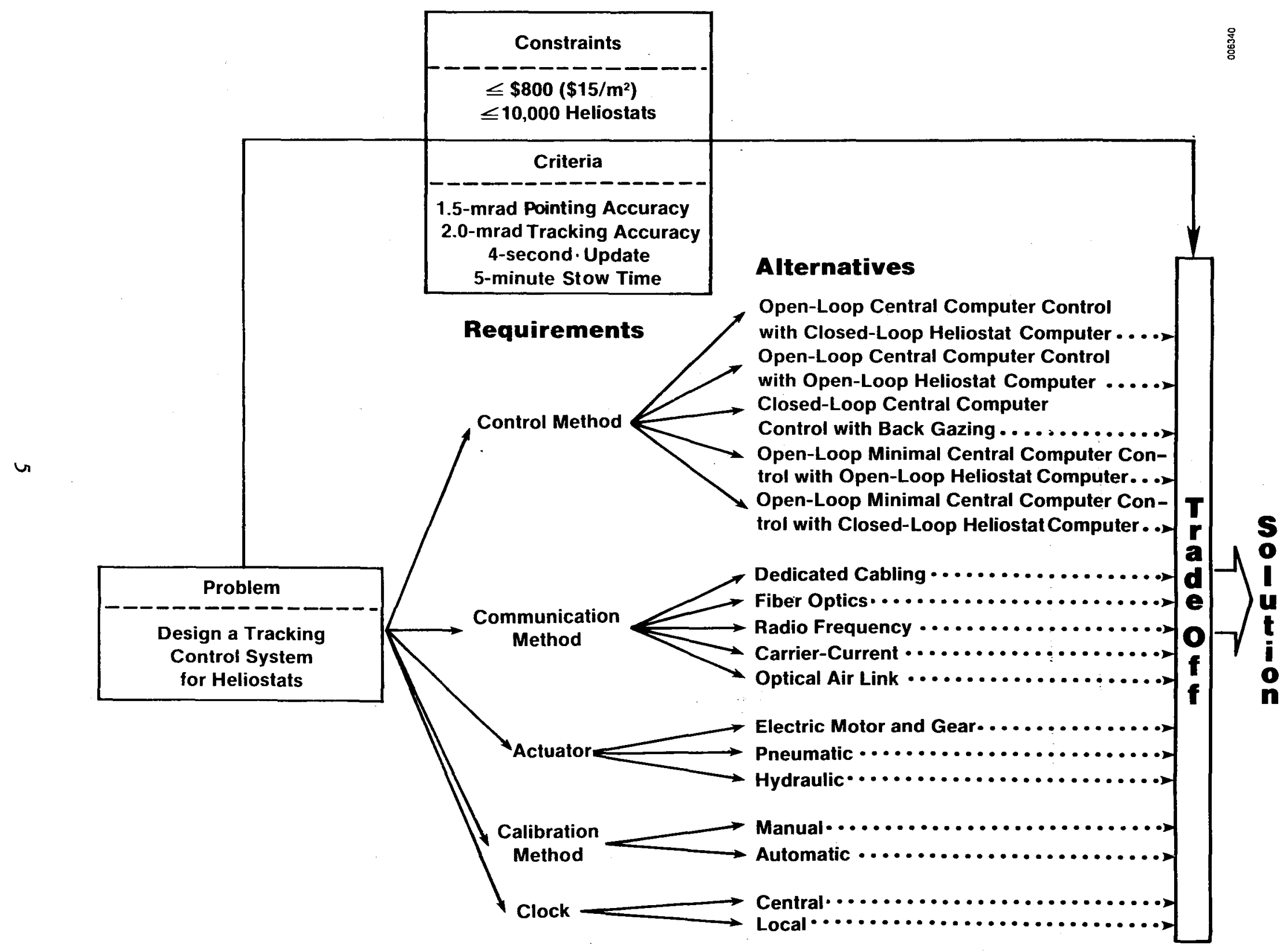

Figure 3-1. Design Problem 


\section{SECTION 4.0}

\section{CONTROL METHODS}

To design a control method for the heliostats of a solar thermal central receiver power plant, one must consider the operational requirements of that plant. For the purposes of this study--i.e., to determine the feasibility and potential of the concepts--we considered only the most fundamental requirements: (1) There must be some central control since it will sometimes be necessary to move a group (or possibly the whole field) of heliostats to a prescribed position; e.g., to prepare for a storm condition or to set up regions of the field for mirror washing. (2) The control should not be dependent upon a prescribed insolation level, since on occasion it will be necessary to track under clouded conditions. (3) Safety precautions must be considered when bringing the reflected sunbeam onto the receiver. (4) There must be some way to calibrate each heliostat with respect to its position and also to focus the beam on the receiver tower. (5) A manual mode of operation must be available at the heliostat for maintenance purposes. (6) Pointing and tracking must be accurate to achieve the best cost and performance.

There are two basic levels of control--the first level is at the central computer and the second level is at the site of each heliostat. At Solar One two control layers are at the second level, and a field computer serves as an intermediary. This study reviews existing control methods at both the central computer and heliostat levels and proposes alternative methods that may enhance performance and reduce control system costs.

In the course of this study we investigated five different control methods. Figure 4-1 shows a simplified block diagram of each method. The five control methods are (1) openloop central computer control with closed-loop heliostat computer control, (2) open-loop central computer control with open-loop heliostat computer control, (3) closed-loop central computer control with back gazing, (4) open-loop minimal central computer control with open-loop heliostat computer control, and (5) open-loop minimal central computer control with closed-loop heliostat computer control. The last two methods are the primary topics of this report.

Open-loop central computer control implies that little or no information concerning the heliostat's actual azimuth and elevation position is known to the central computer. Therefore, an operator in the main control room would not have access to an individual heliostat's position. The exact opposite holds true for closed-loop central computer control in that each heliostat's position is known.

The distinctions between open- and closed-loop heliostat computer control depend on the type of actuator that is used. Hydraulic drives and dc motors require feedback for their control and therefore require closed-loop control. On the other hand, stepper motors do not rely on feedback but require a certain number of pulses per degree of arc; thus, the heliostat computer controller would be open-loop. Greater accuracy may be achieved if the stepper motor drives are operated in a closed-loop mode.

A number of different combinations result from the two layers of control. The characteristics, advantages, and disadvantages of each control technique are discussed in some detail in the next several sections. The first two methods involve open-loop central computer control with closed-loop heliostat computer control (as in Solar One). Had stepper motors been used at Solar One, the heliostat computer control would have been open-loop. The third technique involves direct central computer control of each 


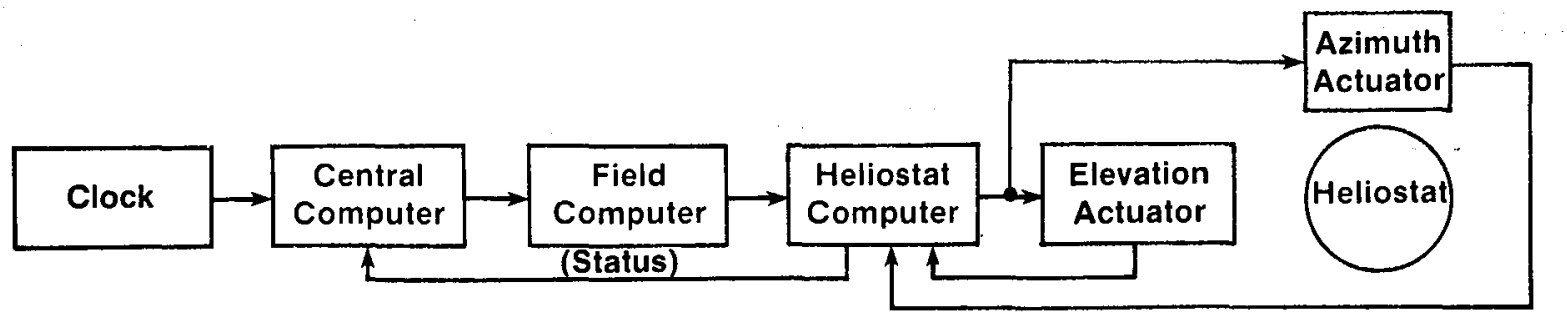

Open-Loop Central Computer Control with Closed-Loop Heliostat Computer Control (Solar One-Barstow, CA)

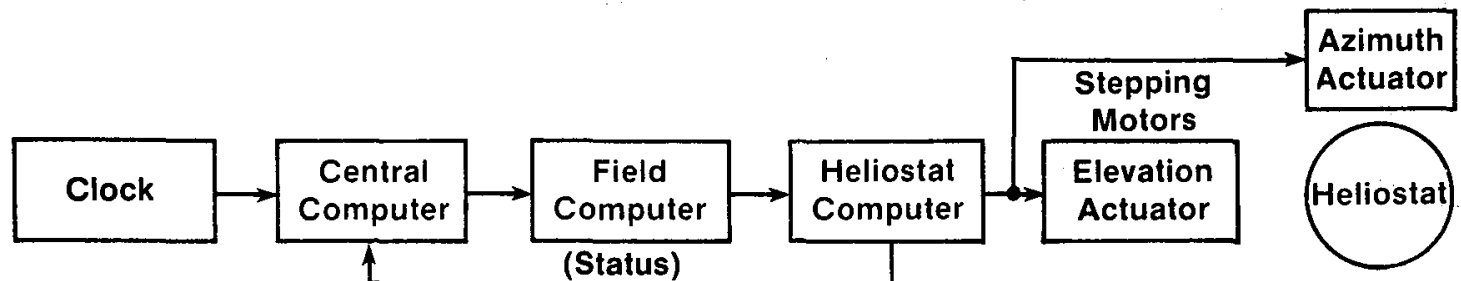

Open-Loop Central Computer Control with Open-Loop Heliostat Computer Control
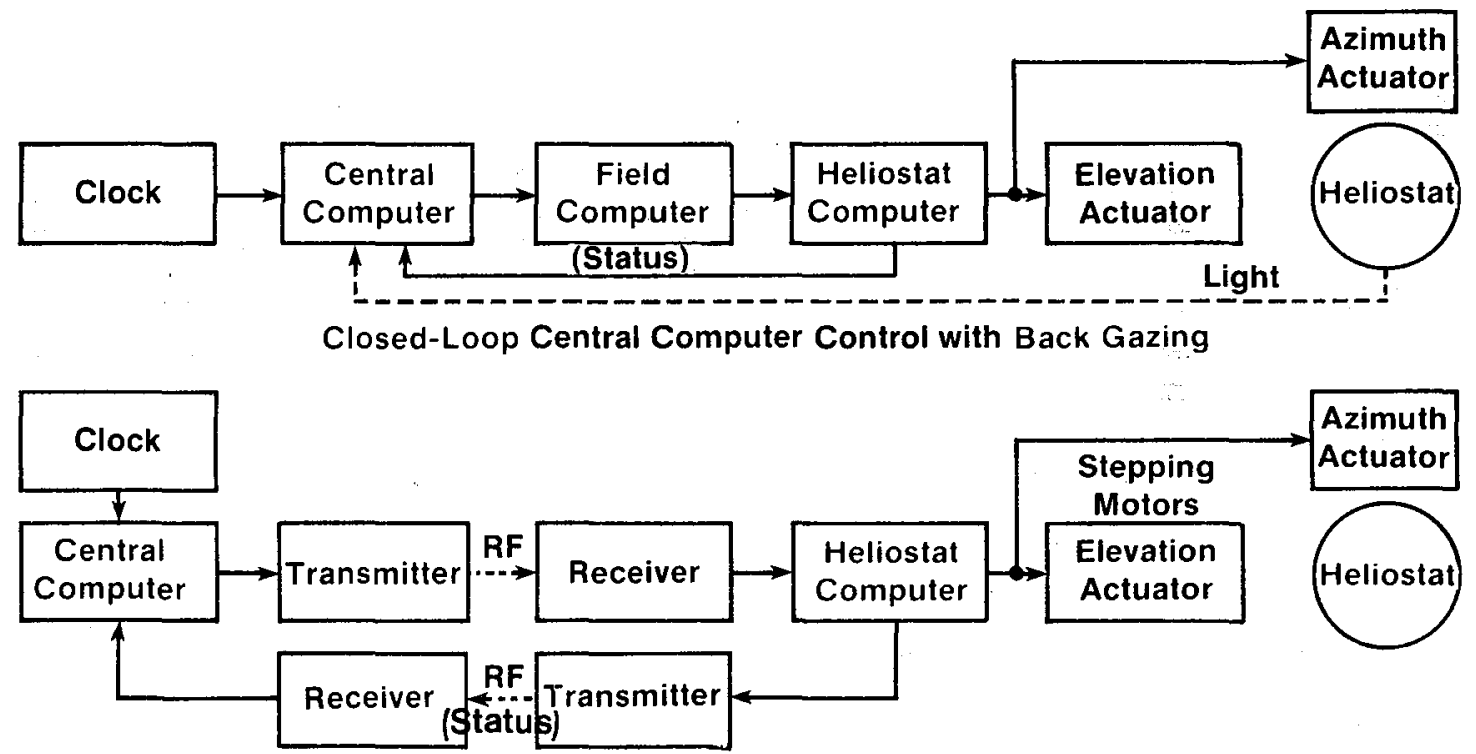

Open-Loop Minimal Central Computer Control with Open-Loop Heliostat Computer Control

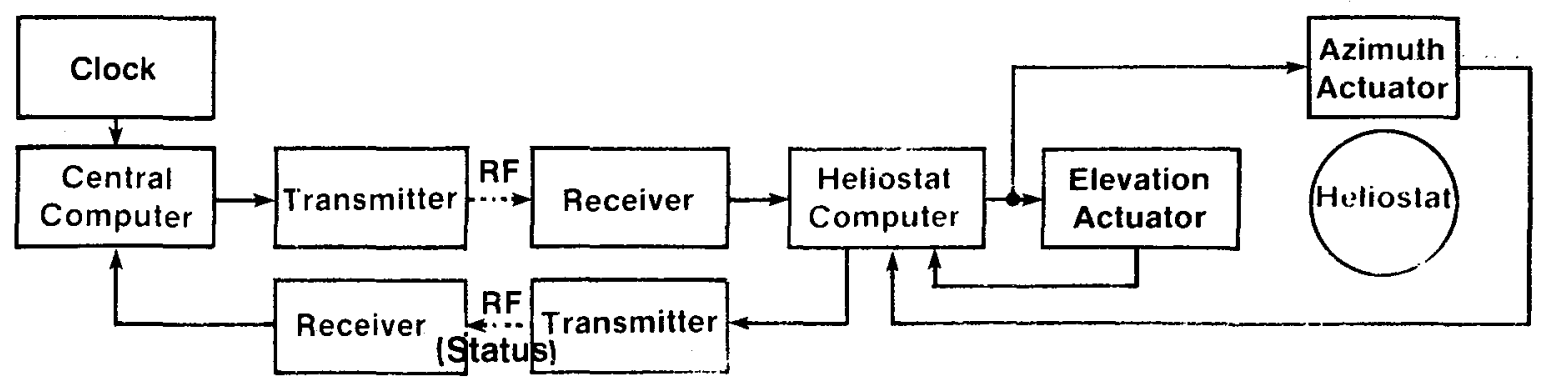

Open-Loop Minimal Central Computer Control with Closed-Loop Heliostat Computer Control

Figure 4-1. Control System Alternatives 
heliostat's actuators. Here a camera or sensor mounted on the central receiver tower looks directly at the heliostat and makes corrections as necessary. The last two control methods with open-loop minimal central computer control require an enhancement of responsibilities by the heliostat computer. Time-of-day information supplied by the central computer allows each heliostat computer to calculate the sun vector and then the heliostat vector. As in the first two control techniques, the type of actuator will determine whether there is closed- or open-loop heliostat computer control. The major elements and issues of each of the five methods follow.

\subsection{OPEN-LOOP CENTRAL COMPUTER CONTROL WITH CLOSED-LOOP HELIOSTAT COMPUTER CONTROL}

Open-loop central computer control with closed-loop heliostat computer control is used at the Solar One prototype plant. The local closed loop refers to a closed loop around the heliostat actuators. In this case, a central receiver gets a clock signal from a federal radio station (WWVB in Fort Collins, Colo.). The clock signal is used by a central computer that calculates the sun vector every second and sends the information to the heliostat computer by shielded cable via an intermediate field computer. The heliostat computer then calculates the azimuth and elevation angles for its location. The actuating signals are then applied to azimuth and elevation actuators. The actuators at Solar One are dc motors, but they could be pneumatic or hydraulic. A 13-bit incremental encoder identifies the axis position to precisely position the heliostat. Only a status signal is fed back from the heliostat to the central computer.

The method is now successfully in use at Solar One. The control scheme is effective given the high mass and stiffness of the heliostat used at that facility. Status reporting is excellent. The many control modes provide a very flexible system for large plants. Lightning has caused some difficulty with the dedicated-cable data links. Data-cable maintenance may become a problem. Control system hardware and fabrication costs are high. The central computer is heavily loaded, which may imply a jump in cost when considering a scale-up in power.

The principle advantage of this control method is that it has a proven track record of operation at the Solar One central receiver facility. Other than heliostat status no information is fed back to the central computer. Operators in the main control room could view this as a disadvantage when trying to remotely fine tune each heliostat. When expanding to a larger facility, the number of heliostats is likely to increase as well, and it may be desirable for the plant's operators to have more information than just the "onof $f$ " status of each heliostat.

The central computer has a limited number of output ports with which to communicate to the field. As a result, an intermediary heliostat field computer is needed to distribute information to each heliostat computer. This potentially can become an unwieldy arrangement when the field size is increased from the $1.0 \mathrm{MW}$ at the Barstow facility to $100 \mathrm{MW}$.

\subsection{OPEN-LOOP CENTRAL COMPUTER CONTROL WITH OPEN-LOOP HELIOSTAT COMPUTER CONTROL}

In the open-loop central computer control with open-loop heliostat computer control method, computer control differs from the first control method only because there is open-loop control of each drive. Stepper motors must be used for actuators in this 
system because the actuators follow absolutely the position instructions of the heliostat computer. Thus, the heliostat operates open loop, and there is no feedback of information from the actuator.

This method does not require position feedback and, therefore, eliminates the cost of a position sensor (the 13-bit incremental encoder noted in the previous control method); however, the step size on standard stepper motors does not provide the 1.5 -mrad pointing accuracy, and a gear reducer must be used with the motor. The rotary position of the gear-reducer output shaft may be accurately controlled by controlling the number of pulses sent to the motor.

The advantages and disadvantages of open-loop central computer control were discussed in Section 4.1. The use of stepper motors as actuators, however, eliminates the closedloop heliostat computer control. We must assume that each pulse causes an exact incremental change for the actuators. Potential errors caused by slippage within the stepper motor or in the gear-reducers would go undetected by the heliostat computer. We do not yet know how serious a problem this may become, but it should be carefully tested under actual field conditions. It appears that stepper motor manufacturers may be rethinking this problem in their designs and that some form of feedback may be incorporated into future products to ensure the required accuracy.

\subsection{CLOSED-LOOP CENTRAL COMPUTER CONTROL WITH BACK GAZING}

In the closed-loop central computer control with back gazing method, a video camera or image sensor mounted on the receiver tower "looks" at the individual heliostats. If the heliostat is correctly pointed, the camera or sensor "sees" a uniform image of the reflected sun. The image may be digitized and the resulting signal may control the heliostat's position through dc motors or hydraulic or pneumatic actuators. This system of fers precise feedback control on each heliostat if enough sensors can be mounted around the tower. For a large power plant, the sensor must be able to select an individual heliostat at a distance of at least $1500 \mathrm{~m}$. The heliostat must also be positioned to reflect an image to the camera or sensor.

The advantage of this control method is that the central computer would have the ability to directly control each heliostat. Compensation for heliostat mounting errors and wind loading is directly provided for. Position sensors for the heliostat actuators are no longer needed. Delays in heliostat response time to central computer commands are reduced. An error model and adaptive controller would not be needed to compensate for heliostat installation errors and to handle the effects of wind loading.

The implementation problems relate to the number of sensors that must be mounted on the tower and the optical resolution required to "select" a heliostat.

The methods by which the tower sensors would be mounted and arranged are not yet clear, nor is the method by which the individual heliostats would be accessed. Although the relative simplicity of the control algorithm is conceptually attractive, the backgazing technique needs a great deal of work to prove its technical feasibility. Of the five control techniques discussed in Sections 4.1-4.5, back gazing will require the greatest level of preliminary study. 


\subsection{OPEN-LOOP MINIMAL CENTRAL COMPUTER CONTROL WITH OPEN-LOOP HELIOSTAT COMPUTER CONTROL}

In the open-loop minimal central computer control with open-loop heliostat computer control method, a central computer generates all the addressing and mode-changing commands, codes them, and sends them to a central transmitter where they are communicated to a receiver located at each heliostat. Each heliostat is uniquely addressed and receives commands intended for itself. As in the first control option, a WWVB receiver connected to the transmitter periodically sends digitized time signals to all heliostat receivers. In contrast to open-loop central computer control (Section 4.1), open-loop minimal central computer control places a greater amount of responsibility on the heliostat computer. First, the sun vector is computed from the received, digitized time signals. Next, the increased computational power of the current generation of control microcomputers enables the heliostat computer to consider predictable errors and random disturbances in the computation of the elevation and azimuth angles. Errors during pedestal installation and mirror assembly are taken into account during initial calibration when error coefficients are first developed (see Appendix A). An adaptive controller (Appendix C) can take care of random disturbances. When requested, the heliostat computer sends the position of the heliostat via a heliostat transmitter to a receiver at the location of the central computer. The central computer assembles the information to give a status report on the heliostat positions in the entire field.

The open-loop heliostat computer indicates that this method does not require position sensors at each heliostat since the method incorporates stepper motors to provide absolute positioning.

Shifting more of the computing responsibility to the heliostat allows for more flexibility in the size of the heliostat field and makes adaptive control and self-diagnosis possible. Stepper motor control accuracy may present potential problems in the implementation of this strategy. A gear reducer must be incorporated to provide the necessary 1.5-mrad pointing accuracy. Slippage and backlash will eventually degrade performance. As was stated in Section 4.2, stepper motor manufacturers are currently trying to correct this problem.

\subsection{OPEN-LOOP MINIMAL CENTRAL COMPUTER CONTROL WITH CLOSED-LOOP HELIOSTAT COMPUTER CONTROL}

The open-loop minimal central computer control with closed-loop heliostat computer control method is similar to the method discussed in Section 4.4 but uses closed-loop control around the actuators. Position feedback is provided to the heliostat computer. Thus, dc motors or pneumatic or hydraulic actuators may be used, and the heliostat is operated in a closed-loop configuration. Recent improvements in dc motor design enhance the prospects for this last strategy. These improvements include neodynium as a new core material, and brushless dc motor development.

The fourth and fifth control methods delegate most of the heliostat computational effort to the heliostat computer. Present prices of microcomputers already allow for this distributed computing capability. Thus either of these two methods would help alleviate the problem associated with the availability of central computer time, particularly as power plants grow in size. Finally, incorporating the self-calibrating controller and, possibly, an adaptive controller into either control strategy would further enhance the heliostat pointing and tracking accuracy. 


\section{SECTION 5.0}

\section{COMMUNICATION METHODS}

Various possibilities exist for communication from the central computer to the heliostat array including dedicated cabling, fiber optics, RF linking, carrier-current linking, and optical air linking. Each of these methods involves individually addressing each heliostat and communicating mode-change and tracking information by serial digital coding. The major factors involved in assessing the optimum communication method are the cost, type of transmission (simplex, half duplex, or full duplex), time it takes to update the control of each heliostat, interrogation rate (communicating the status of each heliostat to the central computer), flexibility (applicable to large or small plants), and serviceability. Table 5-1 summarizes the potential communication methods.

Costs have been determined in 1982 dollars.

\subsection{DEDICATED CABLING}

The cost of the dedicated cabling used at Solar One (see Table 5-1, column 1) is approximately $\$ 250$ per heliostat. Lightning-caused electromagnetic interference (EMI) and maintenance problems seem to indicate that there may be more reliable ways to accomplish this communication. Control system cost for Solar One [3], using dedicated cable communication links, is itemized in Table 5-2.

\subsection{FIBER OPTICS LINK}

Martin Marietta has done considerable work with a fiber optic communication system [7] (see Table 5-1, column 2). This approach would reduce the noise problem and the potential for lightning damage. It would also reduce the cabling cost, mainly because the cable itself costs less. The cabling estimate is $\$ 116$ per heliostat. The potential exists for considerably higher data rates than with direct cabling. Further work with the distributed computer system has resulted in lower costs at each level. Table 5-3 itemizes costs [8] for the second-generation control system using fiber optic communication links.

\subsection{RADIO FREQUENCY LINK}

For a few years, integrated circuits have been produced for RF remote control systems; i.e., TV receivers and model airplanes and boats. Transmitter and receiver chips are now available from Motorola, National Semiconductor, and Plessey Semiconductor for such remote control applications or for pager applications. Data on these devices justify the entries in Table 5-1, column 3. These chips are suitable for communication using frequency shift keying and a carrier frequency of $100 \mathrm{MHz}$. The low-cost $(\$ 12)$ transmitterreceiver at each heliostat makes the method attractive. Data rates are limited, and an antenna is required at each heliostat. A $100-\mathrm{MHz}$ carrier would require a $75-\mathrm{cm}$ whip antenna.

Table 5-4 itemizes SERI's estimated control system cost using this RF scheme with openloop heliostat control. 
Table 5-1. Heliostat Communication Systems

\begin{tabular}{|c|c|c|c|c|c|}
\hline Characteristic & $\begin{array}{l}\text { Dedicated Cabling } \\
\text { (Solar One) }\end{array}$ & $\begin{array}{c}\text { Fiber Optics } \\
\text { (Second Generation) }\end{array}$ & $\begin{array}{c}\text { Radio } \\
\text { Frequency }\end{array}$ & Carrier-Current & $\begin{array}{l}\text { Optical } \\
\text { Air Link }\end{array}$ \\
\hline $\begin{array}{l}\text { Data transmission } \\
\text { speed (kbaud) }\end{array}$ & 10 & 76.8 & 10 & 4 & 100 \\
\hline $\begin{array}{l}\text { Data reliability } \\
\text { estimated BER* }\end{array}$ & $10^{-5}$ & $10^{-6}$ & $10^{-5}$ & $10^{-5}$ & no data \\
\hline Type of transmission & half duplex & half duplex & full duplex & half duplex & simplex \\
\hline Coding & $N R Z$ & biphase mark & Manchester & Manchester & Manchester \\
\hline $\begin{array}{l}\text { Electromagnetic } \\
\text { interference } \\
\text { (EMI) }\end{array}$ & some problems & no problem & no problem & no problem & no problem \\
\hline Reliability & high & high & high & high & high \\
\hline Serviceability & hard & hard & moderate & moderate & moderate \\
\hline Sun-time update (s) & 1 & 1 & 4 & 4 & 1 \\
\hline $\begin{array}{l}\text { Field status inter- } \\
\text { rogation rate }(\mathrm{s})\end{array}$ & 8 & $\begin{array}{l}8 \text { (capable } \\
\text { of higher rate) }\end{array}$ & 8 & 20 & $\begin{array}{l}8 \text { (capable of } \\
\text { higher rate) }\end{array}$ \\
\hline $\begin{array}{l}\text { Equipment cost - } \\
\text { total } \$\left(\$ / \mathrm{m}^{2}\right)^{* *}\end{array}$ & $\begin{array}{l}2710 \\
(50)\end{array}$ & $\begin{array}{l}1343 \\
(25)\end{array}$ & $\begin{array}{l}474 \\
(9)\end{array}$ & $\begin{array}{l}502 \\
(10)\end{array}$ & $\begin{array}{l}716 \\
(13)\end{array}$ \\
\hline Risk & low & low & medium & low & medium \\
\hline Advantages & already built & $\begin{array}{l}\text { high data rates, } \\
\text { low noise, } \\
\text { low parts counts }\end{array}$ & $\begin{array}{l}\text { inexpensive, } \\
\text { low noise, } \\
\text { eliminates } \\
\text { data cables }\end{array}$ & $\begin{array}{l}\text { eliminates } \\
\text { data cables, } \\
\text { low noise }\end{array}$ & $\begin{array}{l}\text { eliminates } \\
\text { data cables }\end{array}$ \\
\hline Disadvantages & $\begin{array}{l}\text { noisy, cable } \\
\text { cost, cable } \\
\text { laying, cable } \\
\text { maintenance }\end{array}$ & $\begin{array}{l}\text { cable laying, cable } \\
\text { maintenance }\end{array}$ & $\begin{array}{l}\text { antenna } \\
\text { requirement }\end{array}$ & $\begin{array}{l}\text { medium data } \\
\text { rates }\end{array}$ & $\begin{array}{l}\text { weather } \\
\text { sensitivity, no } \\
\text { interrogation }\end{array}$ \\
\hline
\end{tabular}


Table 5-2. Solar One Control System Cost (1818 heliostats)

\begin{tabular}{lr}
\hline Cabling & $\$ 250$ \\
Central computer & 165 \\
Field computer/heliostat computer & 1100 \\
Position encoders (2) & 400 \\
Drive motors (2) & 300 \\
Beam characterization system & 495 \\
& Total \\
& $\$ 2710$ per heliostat \\
& or approximately $\$ 50 / \mathrm{m}^{2}$ \\
\hline
\end{tabular}

Table 5-3. Second-Generation Control System Cost $(2000$ heliostats)

\begin{tabular}{lr}
\hline Cabling (fiber optics) & $\$ 116$ \\
Central computer & 78 \\
Field computer/heliostat computer & 457 \\
Position encoders (2) & 401 \\
Drive motors (2) & 252 \\
Beam characterization system & 39 \\
& Total \\
& $\$ 1343$ per heliostat \\
& or approximately $\$ 25 / \mathrm{m}^{2}$ \\
\hline
\end{tabular}

\subsection{CARRIER-CURRENT LINK}

Another communication alternative uses the power cables to transmit control signals to the heliostats. This is called carrier-current transmission. All heliostats must be supplied with power for the control motors and the heliostat computer. In this method the modulated control signal is coupled to the ac power line at the central computer and picked off the ac power line at the addressed heliostat where the signal is demodulated and available for control. Sandia Laboratories [4] designed a power cable carrier-current control system to provide control signals to a tracking trough collector. At the time of the Sandia study [4] the hardware was too expensive for this application $(\$ 600-\$ 800$ for the transmitter and receiver) and also was too slow (60 baud) for effective application to large heliostat fields. However, this is not true today since National Semiconductor recently (1983) announced the availability of an integrated-circuit carrier-current transceiver [2], which is the heart of a sophisticated ac power-line link. This single-chip transceiver operates up to $4 \mathrm{kbaud}$ and costs about $\$ 12$. If this communication technique were applied to a field of 2000 heliostats, SERI's estimated cost using open-loop heliostat control would be broken down as shown in Table 5-5.

Carrier-current systems are usually quite susceptible to EMI. Lightning is a significant factor in heliostat fields, so carrier-current systems may require error-correcting codes such as Manchester encoding or MADCODE [9] to secure the data communication. Manchester encoding is an evolved form of the standard nonreturn-to-zero technique. Manchester encoding represents bit levels by level transitions, with the direction of the 
Table 5-4. RF Control System Cost

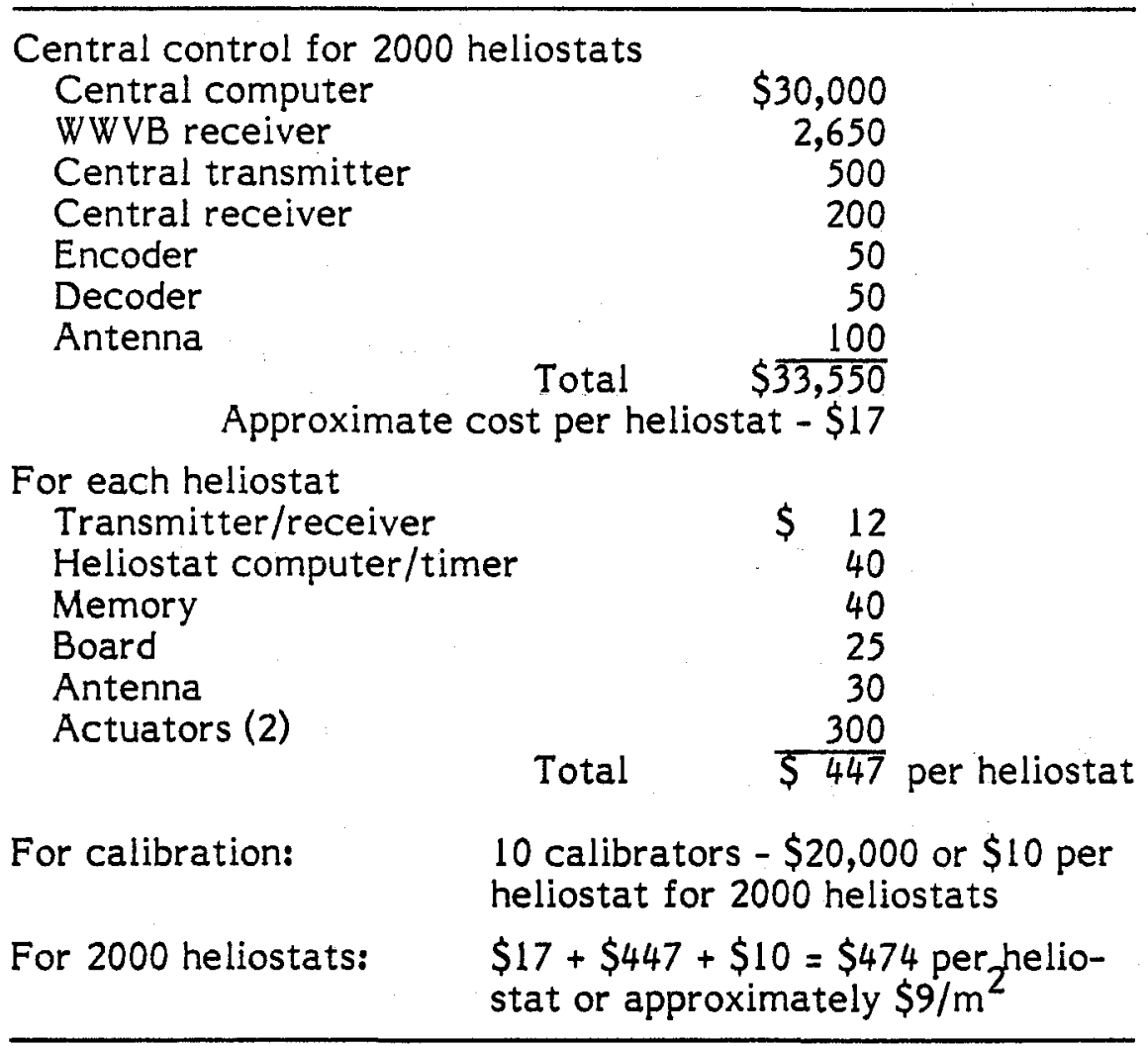

Table 5-5. Carrier-Current Control System Cost

\begin{tabular}{|c|c|}
\hline $\begin{array}{l}\text { Central control for } 2000 \text { hel } \\
\text { Central computer } \\
\text { Central transceivers } \\
\text { Line couplings } \\
\text { WWVB receiver } \\
\text { Approximate cos }\end{array}$ & $\begin{array}{lr}\text { iostats } & \$ 30,000 \\
450 \\
300 \\
\\
2,650 \\
\text { Total } \$ 33,400 \\
\text { st per heliostat }-\$ 17\end{array}$ \\
\hline $\begin{array}{l}\text { Oor each heliostat } \\
\text { Line couplings } \\
\text { Transceiver } \\
\text { Heliostat computer/timer } \\
\text { Memory } \\
\text { Board } \\
\text { Actuators (2) }\end{array}$ & $\begin{array}{l}\$ 40 \\
30 \\
40 \\
40 \\
25 \\
300 \\
\$ 475 \text { per heliostat }\end{array}$ \\
\hline For calibration: & $\begin{array}{l}10 \text { calibrators }-\$ 20,000 \text { or } \$ 10 \text { per } \\
\text { heliostat for } 2000 \text { heliostats }\end{array}$ \\
\hline For 2000 heliostats: & $\begin{array}{l}\$ 17+\$ 475+\$ 10=\$ 502 \text { per heliostat } \\
\text { or approximately } \$ 10 / \mathrm{m}^{2}\end{array}$ \\
\hline
\end{tabular}


change determining the value of the bit. Each transition must occur during the middle of the half-clock cycle. If it occurs elsewhere an error is detected. The Manchester code is self-clocking. It may be desirable to use such error-correcting encoders with the RF systems as well to further reduce a rather low bit-error rate. A summary of the carriercurrent data link is given in Table 5-1, column 5.

\subsection{OPTICAL AIR LINK}

The final communication alternative considered is the optical air link. Essentially this method involves an optical transmitter (laser or LED) at the central tower and optical detectors at each heliostat. The optical transmitter will be able to communicate over a dispersed heliostat field by one of two methods: wide-angle beam or computer-driven prisms. The dispersed wide-angle beam would use an optical source with a cone of $0.2-0.3 \mathrm{~N} . A$. (numerical aperture, approximately $23^{\circ}$ for $0.2 \mathrm{~N}$. A.), which implies that 12-18 transmitters must be mounted on the tower to cover the entire heliostat field. Addressing the heliostat in the sector of the particular optical transmitter would be done serially. The second technique involves the use of two computer-controlled prisms. The optical source would be fixed, and the two prisms would deflect the beam appropriately in the $\mathrm{X}$ and $\mathrm{Y}$ directions for point-to-point communication with an addressed heliostat.

Transmitter power would have to be about $2 \mathrm{~W} \mathrm{cw}$ (continuous wave). Currently available laser diodes are $100 \mathrm{~mW} \mathrm{cW}$ and cost $\$ 1500$ each. Using the wide-angle beam transmission for this application would require about 300 diodes for the entire system. Detectors can be obtained for $\$ 10$ each. Table 5-6 breaks down SERI's estimated cost for an optical air link using open-loop heliostat control and simplex communication.

One problem that may arise with this method is the dissipation of the diode power around the transmitter. There are indications that the cost-reduction potential for laser diode devices is very good. The central transmitter cost could conceivably be cut in half, which would reduce the per-heliostat, per-square-meter cost to $\$ 11$.

Table 5-6. Optical Air Link Control System Cost

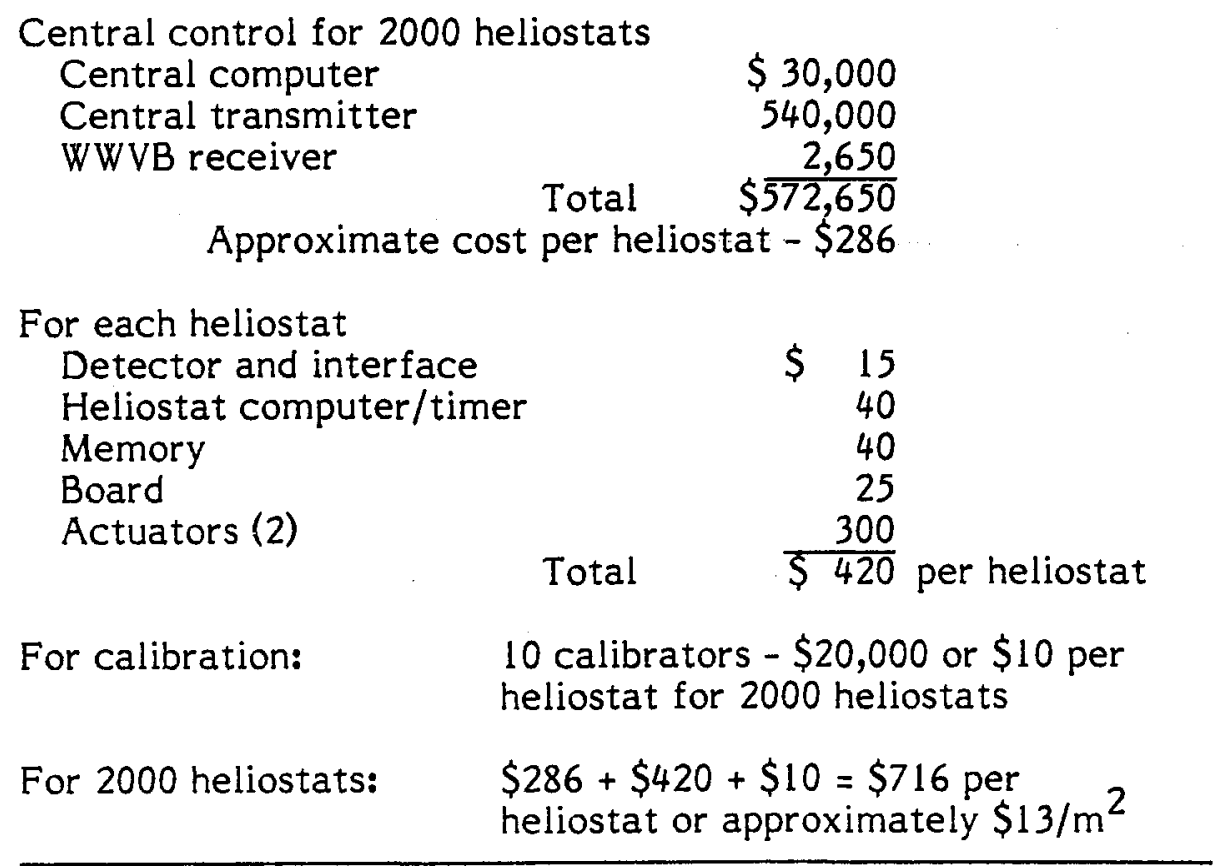




\section{SECTION 6.0}

\section{ACTUATOR, CALIBRATION METHOD, AND CLOCK}

As was discussed in Section 3.0, the various alternative control methods and communications methods must take into account the type of actuator, the calibration method, and the clock that will be employed in the total design. The selection of the actuator itself will partly determine which of the five types of control systems will be used. We now discuss briefly the actuator, the calibration method, and the clock.

\subsection{ACTUATOR}

Actuators that may be used for heliostat positioning include ac induction motors and gear drives, dc motors and gear drives, stepper motors and gear drives, pneumatic valves with piston and cylinder, and hydraulic valves with piston and cylinder. Each of the above actuators except stepper motors and gear drives would require position feedback to accurately point the heliostat. Hydraulic and pneumatic systems achieve high mechanical advantages but would require fluid reservoirs for groups of heliostats. In addition, electrically driven actuators are replacing hydraulic systems in the rapidly emerging robotics industry.

The selection of an actuator is based on cost, tracking accuracy, pointing accuracy, reliability, and ease of maintenance.

\subsection{CALIBRATION METHOD}

The calibration referred to here is the alignment of the heliostat-reflected sunbeam or moonbeam with the tower according to the time of day. This may be done manually or automatically. Manual calibration involves periodically placing a sun (or moon) sensor on each heliostat and making software or mechanical adjustments to locate the beam on the receiver tower properly. A sun or moon sensor could be permanently installed on each heliostat for this purpose.

Automatic calibration would involve a periodic computer-controlled adjustment of each heliostat to accurately position the reflected sunbeam (or moonbeam) on the receiver tower or a field sensor. Sof tware could then be adjusted according to that positioning.

\subsection{CLOCK}

The time-of-day clock could be a centrally located means of receiving time signals generated by the National Bureau of Standards (NBS) and then communicating the time or calculated sun-position information to each heliostat. Standard WWVB receivers are available for such receptions. These clocks are now available for under $\$ 400$. A local clock could be installed at each heliostat as an alternative. This method would involve periodic calibration either manually or automatically. 


\section{SECTION 7.0}

\section{HELIOSTAT CONTROLLER SELECTION}

The selection process now involves choosing between the alternatives for each of the five major system requirements: control method, communication method, actuator, calibration method, and clock. Most of this study was committed to identifying, studying, and evaluating innovative approaches to the control method and the communication method [10].

\subsection{CONTROL METHOD SELECTION}

It has already been determined that open-loop control of the entire system may provide the best tracking scheme. Heliostats track according to the sun equation and thereby do not have to "see" the sun (see Fig. 7-1).

Closed- or open-loop control at the heliostat depends on the actuator system. Stepper motors and gear drives can be used with open-loop control. This method costs less, satisfies the constraints, and is more reliable than pneumatic or hydraulic actuators.

It is desirable to shift more of the computational responsibility to the heliostat computer because of the possibility of overloading the central computer in scale-up to $100-\mathrm{MW}_{\mathrm{e}}$ plants. Using enhanced heliostat computers will also provide the opportunity for local adaptive control and beam-error correction ability. Further, the elimination of field computers is desirable.

The back-gazing method is too complex at the present time. Software problems and problems with physically mounting the sensors are still unknown.

The control methods we selected for further study are open-loop minimal central computer control with either open-loop or closed-loop heliostat computer control. At the present time, these two candidates appear to be the most promising approaches studied.

\subsection{COMMUNICATION METHOD SELECTION}

Table 5-1 rather clearly delineates the advantages and disadvantages of each of the communication methods. As a result of the appropriate weighting of cost, type of transmission, update time, interrogation rate, flexibility, and serviceability in a decision matrix, we selected an RF communication link. The carrier-current method is a close. second choice and should be examined further.

\subsection{ACTUATOR SELECTION}

The actuator we selected is a stepping motor with a gear drive, which is coupled with the control method selection. Stepping motors with gear drives eliminate local position feedback at each heliostat and provide a more reliable subsystem than either pneumatic or hydraulic actuators. Accuracy could be enhanced, however, by providing position feedback. 


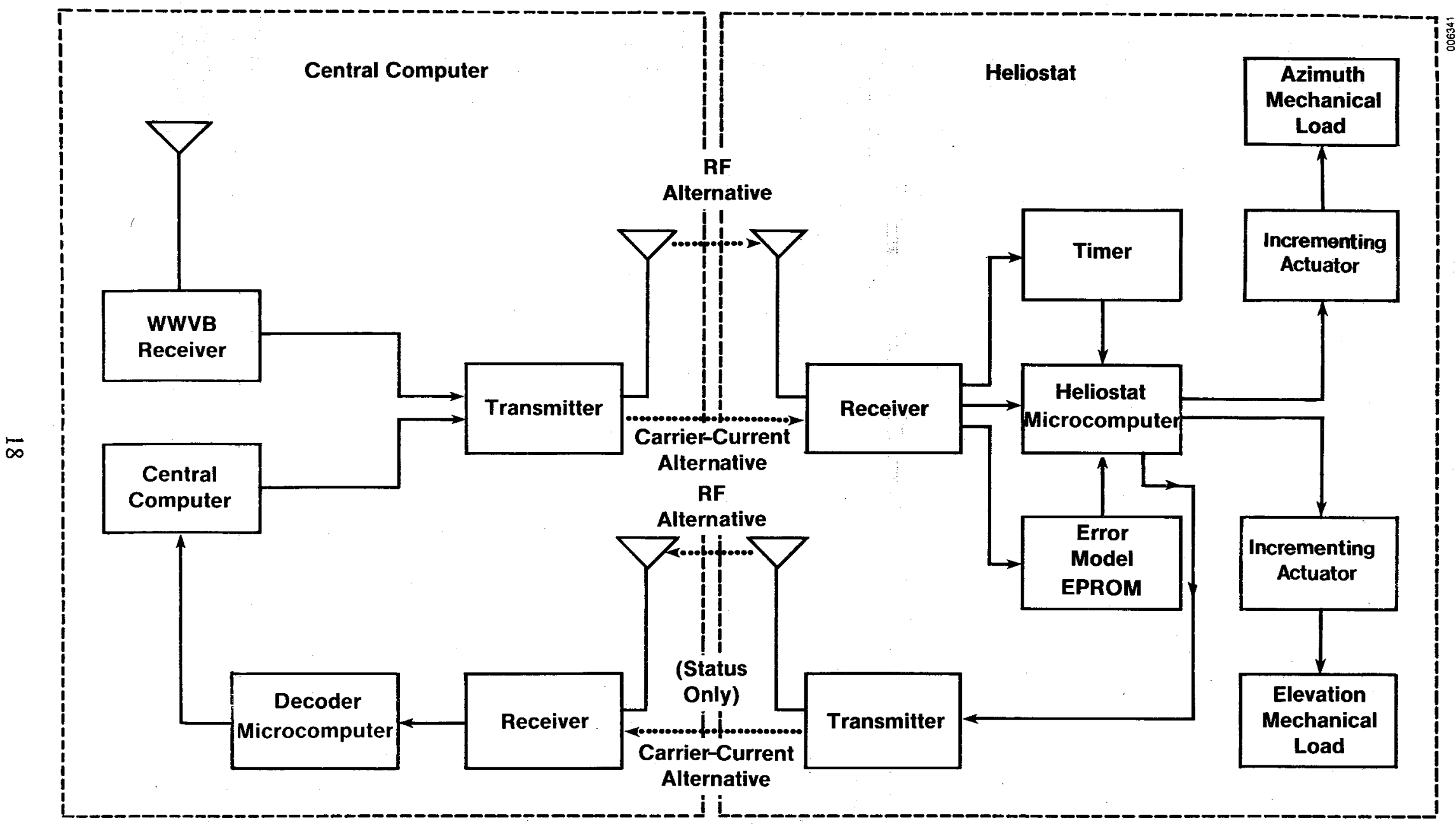

Figure 7-1. Proposed Heliostat Control System-Open-Loop Minimal Central Computer Control with Open-Loop Heliostat Computer Control 


\subsection{CALIBRATION METHOD SELECTION}

Based on system cost constraints, we selected the manual calibration method. Periodic manual calibration can be combined with preventive maintenance activity on a six-month cycle. The method would involve manually mounting a sun sensor on a heliostat such as in Fig. 7-2 (see part B of diagram), pointing the heliostat to a target, and then estimating the coefficients of an error model that would be used during the tracking mode. This procedure must be followed at each heliostat. The new error parameters should be stored in a nonvolatile read-only memory.

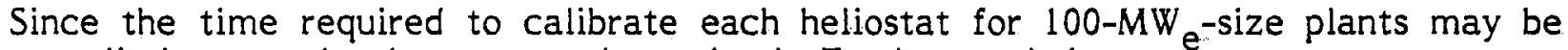
unrealistic, our selection may not be optimal. Further study is necessary.

\subsection{CLOCK SELECTION}

We selected a central clock source. A single high-quality WWVB receiver may be used to receive NBS clock signals and transmit time-of-day information to the entire heliostat field. A local clock in the heliostat microcontroller will keep the time and will be synchronized at least once every hour by the NBS clock signal.

\subsection{SELECTION SUMMARY}

After analyzing the control methods with different communication alternatives, we concluded that the control system shown in Fig. 7-1 is the optimum selection in light of the following observations:

- The estimated cost is approximately $\$ 500$ per heliostat, or less than $\$ 10 / \mathrm{m}^{2}$.

- The data rate is consistent with the information that must be communicated.

- The error rate is low.

- EMI problems are minimal.

- Cable-maintenance problems are eliminated.

- The field computers are eliminated.

- The system is capable of controlling less massive and less stiff structures that might require adaptive control.

- The system is capable of maintaining heliostat tracking control for at least two hours if the central computer fails to transmit time signals.

- The heliostat controller can be applied to small dedicated systems for industrial process heat (IPH) applications.

- The central computer load can be reduced.

The system that we selected uses open-loop heliostat computer control (method 4) requiring stepping motors. The closed-loop heliostat computer control system (method 5) could also be used. Pointing and tracking accuracy would be increased, but that would require the addition of position encoders, which would increase the cost to about $\$ 700$ per heliostat, or $\$ 13 / \mathrm{m}^{2}$. 


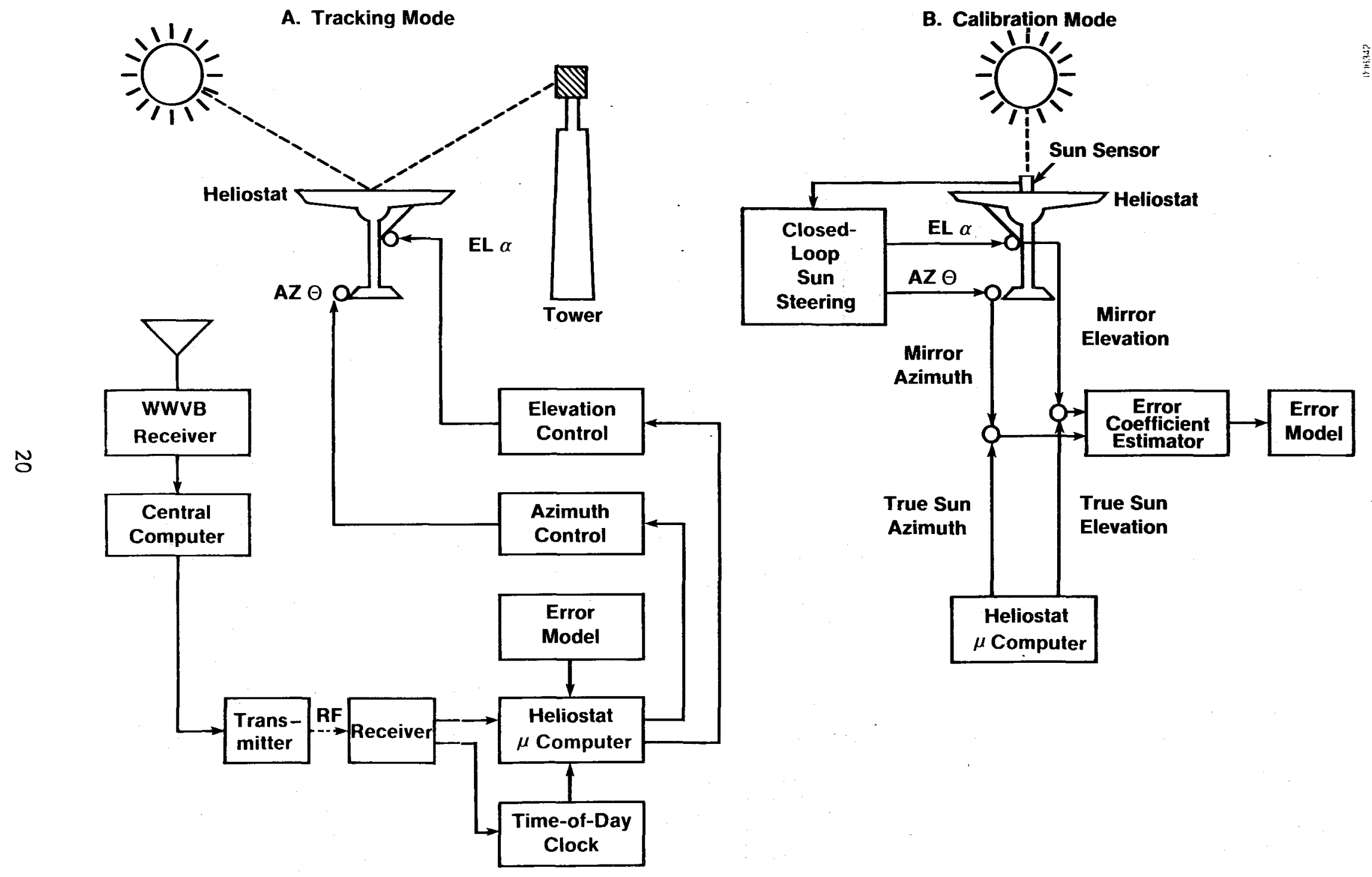

Figure 7-2. Tracking and Calibration Modes 
The collector control and communication subsystem would work as follows: The heliostat would be in a stowed position at the beginning of the day. The central computer would address all heliostats in the field with a "wake-up" signal. The heliostat computer would then make a system check of the heliostat mechanisms. A fault condition would interrupt the system check and place the heliostat in the manual mode of operation. This condition would be reported at a later status check. In the absence of a fault condition, the heliostat would receive a time-of-day signal that would start the time-of-day clock. A clock check would then be made to ascertain whether the clock signal properly started the clock at the heliostat computer. Next, the central computer would send a tracking mode signal to all heliostats. This signal would initiate the calculation of the sun vector at each heliostat depending on its position in the field. The sun vector would then be added to the tower vector to get the inertial pointing vector, which must then be modified by an error model (to be discussed in the following paragraph) to get the mirrorpointing vector. Groups of heliostats would then be brought onto the target according to a safe start-up procedure. The heliostat, under the control of the heliostat computer, would track the sun. The heliostat computer would output control action signals to the azimuth and elevation actuators every 4 seconds. The central computer would send synchronizing time-of-day signals to the heliostat hourly.

The error vector (see Appendix A) [6] would be determined as follows: After the heliostat has been physically installed, it would be calibrated with a closed-loop position control system using a sun sensor mounted on the heliostat. The mirror azimuth and elevation signals would then be compared with the true or calculated azimuth and elevation signals. An estimation algorithm would then be used to determine the error coefficients that would lead to the error vector. Figure 7-2B shows the calibration scheme, which is a manual operation that must be done to each heliostat periodically (possibly every six months). Using this method pointing accuracy would be approximately 1.5 mrad.

Recent advances in microcontroller technology (see Appendix B) make it possible to implement an on-line parameter identification and control algorithm. A self-tuning regulator that directly relates the controller coefficients to the identified model parameters has been suggested (see Appendix C) [7]. The algorithm would handle random loads or disturbances. The memory required for this algorithm is estimated to be 4 kbytes of read-only memory (ROM) and 0.5 kbytes of random-access memory (RAM).

The software that must be developed for this controller would include the following programs:

- Estimation algorithm for the error vector

- Address decoder

- Wake-up routine

- Targeting routine

- Fault routine

- Clock-synchronization routine

- Sun-vector calculation

- Actuator-signal calculation

- Self-tuning regulator algorithm 
- Stow routine

- Status report.

Some problems that will require more research include the following areas:

- It is not clear what the tracking accuracy could be if the self-calibrating technique is used. Baheti and Scott [6] indicate that it would be 3-4 mrad; 2 mrad would be desirable. A maximum-likelihood estimator rather than a least-squares estimator as used in Ref. 5 may realize the greater tracking accuracy.

- Since the heliostats represent many metal surfaces in the field of communication, a phenomena known as multipath may exist. This means that the propagation medium contains several distinguishable "paths" connecting the transmitter and receiver. Signals traversing each path will arrive at the receiver sequentially causing destructive or constructive interference. This phenomenon has recently been investigated [7] at Solar One with the results indicated previously. More research will be necessary with the actual transmitter-receiver.

- It is not completely clear, at this time, whether an RF communication link with a one-mile range and this kind of control function will require an FCC license.

- The third-generation heliostat has not yet been identified, so the elevation and azimuth actuators, with which this system must interface, have not been determined. 


\section{SECTION 8.0}

\section{PROPOSED RESEARCH AND EXPECTED RESULTS}

Research should be conducted in the following areas:

- Design, build, test, and evaluate an RF data-link prototype

- Design, build, test, and evaluate a carrier-current data-link prototype

- Determine a suitable chip configuration for various heliostat components including the transmitter-receiver, address decoder, and microcontroller

- Interface microcontroller hardware with selected data-link and heliostat drives

- Design software for the heliostat microcontroller that will combine the selfcalibrating principle of Baheti with one of the data-linking systems outlined above

- Design software for the self-tuning control algorithm

- Test the combined communication-control design with a simulated central computer transmitter and heliostat drive system. Determine response times to various stimuli; e.g., heliostat drive malfunction, high wind condition, status request from the central computer, etc.

- Install selected hardware and software at the SERI test site.

Acceptability will be defined as achieving a:

- Capability of addressing 10,000 heliostats, communicating time of day and up to 16 mode changes, and receiving heliostat status

- Minimum pointing accuracy of $1.5 \mathrm{mrad}$

- Minimum tracking accuracy of $2.0 \mathrm{mrad}$

- Controller cost of $\$ 10 / \mathrm{m}^{2}$ or less, excluding the drive mechanism. 


\section{SECTION 9.0}

\section{CONCLUSIONS}

As noted in the Introduction, heliostats that cost considerably less than the current second-generation heliostat are badly needed. This study of control methods offers a viable approach to the realization of competitive future cost goals for control and communication. When the RF control system or the carrier-current control system designs are applied to the current $54-\mathrm{m}^{2}$ second-generation heliostat, cost savings of approximately $60 \%$ are realized.

More specifically, these two heliostat control methods reduce the second-generation control system cost of $\$ 25 / \mathrm{m}^{2}$ per heliostat to $\$ 2 / \mathrm{m}^{2}$ for the RF system and $\$ 10 / \mathrm{m}^{2}$ for the carrier-current system--cost savings of $\$ 16 / \mathrm{m}^{2}$ and $\$ 15 / \mathrm{m}^{2}$, respectively.

These fost savings will significantly contribute to the overall cost goal reduction of $\$ 50 / \mathrm{m}^{2}$ for installed heliostat systems. As discussed in Section 1.0, this cost includes the communication system, the control system, and the actuators.

The scheme proposed here for heliostat control places all computational control effort at the heliostat. An error model would be used to realize the necessary pointing accuracy (see Appendix A). A self-tuning regulator may be used to handle random loading effects (see Appendix C). Mode changes and clock signals would be communicated from the central computer to the heliostat using pulse code modulation (Manchester coding) and frequency shift keying of an RF signal with a $100-\mathrm{MHz}$ carrier or frequency shift keying of power-cable carrier currents. The open-loop heliostat control relies on the manual calibration technique used to generate the error model and the computation at the heliostat of the azimuth and elevation actuation signals. The azimuth and elevation angles are obtained from the time-of-day clock, inertial coordinates, error model, and a locally computed sun vector. These signals would be applied to the selected actuator. 


\section{SECTION 10.0}

\section{REFERENCES}

1. Edelstein, R. B., "Value-Based Costs for Advanced Solar Systems," Review of Polymer Requirements for Solar Thermal Systems, SERI/CP-251-1419, Golden, CO: Solar Energy Research Institute, Aug. 1981, pp. 75-110.

2. Sandia National Laboratories, Second-Generation Heliostat Evaluation--Summary Report, SAND 81-8024, Livermore, CA: Sandia Livermore Heliostat Division, Sandia National Laboratories, Jan. 1982.

3. Martin Marietta Corporation, Second-Generation Heliostat Development, SAND 81-8176, Sandia National Laboratories, Apr. 1981, pp. 5-13, 5-20, 5-21.

4. Alvis, R., et al., "Microprocessor-Based Carrier Control," SAND 82-0001, Albuquerque, NM: Sandia National Laboratories, Mar. 1982.

5. Lee, M., "A New Carrier-Current Transceiver IC," IEEE Transactions on Consumer Electronics, Vol. CE-28, No. 3, Aug. 1982, p. 409.

6. Baheti, R. S., and P. F. Scott, "Design of Self-Calibrating Controllers for Heliostats in a Solar Power Plant," IEEE Transactions on Automatic Control, Vol. AC-25, No. 6, Dec. 1980, p. 1091.

7. Sheirah, M. A., O. P. Malik, and G. S. Hope, "Self-Tuning Microprocessor Universal Controller," IEEE Transactions on Industrial Electronics, Vol. IE-29, No. 1, Feb. 1982, pp. $31-\overline{38}$.

8. Hart, W., personal communications, Martin Marietta Corporation, Denver, CO, June 1982.

9. Madison, L. D., "Coding for Single-Line Transmission," NASA Tech Briefs, Spring 1983 and personal communication, June 1984.

10. Pearson, J., and B. Chen, "Heliostat Control System Strategies," Proceedings of the ASME Annual Meeting, Boston, MA: American Society of Mechanical Engineers, Nov. 1983. 


\section{APPENDIX A}

\section{SELF-CALIBRATING CONTROLLERS}

The purpose of a self-calibrating controller is to reduce installation and drive errors in a heliostat. During the initial calibration process and at periodic calibration intervals thereafter, the tracking of the sun provides a position reference with the heliostat pointed directly at the sun. The coefficients of an error model representing installation and drive errors would be determined by comparing the true sun angles with the measured drive angle. These error coefficients would then be stored in the heliostat computer in a nonvolatile ROM and would then be used by the heliostat under normal operating conditions to correct commands to drive the actuators. The use of such a model would help to reduce the installation and alignment effort for the heliostats, as well as the machining requirements for the drive wheels.

The primary sources of error, which are compensated for by the self-calibrator that now permits open-loop control of the heliostat and its mirror assembly, consist of (1) pedestal axis tilt, (2) azimuth and elevation, and (3) drive-wheel radius tolerances. A study by Baheti and Scott [6] predicts that the use of such a calibrator will reduce pointing errors significantly. For a heliostat $1300 \mathrm{~m}$ away from the receiving tower, the pointing error would be $30 \mathrm{~m}$ without the error correction model and less than $1.5 \mathrm{~m}$ with the error correction model.

A self-calibrating controller has two modes of operation, calibration and tracking mode. In the calibration mode errors during heliostat installation and errors in the drive system are determined. The microcontroller generates a linear model in spherical coordinates that relates the mechanical system errors with the azimuth and elevation angles. The model parameters that are computed using least-squares estimation are then stored in memory and used to compensate for heliostat errors during operation in the tracking mode. 


\section{APPENDIX B}

\section{INTEL 8051 MICROCONTROLLER}

The 8051 family is based on an HMOS microcomputer chip designed specifically for the control environment. The control enhancements include a Boolean processor, bitaddressable data RAM, two counter/timers, and a serial $\mathrm{I} / \mathrm{O}$ port.

The 8051 has 4 kbytes of on-chip ROM and 128 bytes of on-chip RAM. It is capable of addressing 64 kbytes each of program and data memory. The arithmetic processor will handle 8-bit binary and $B C D$ arithmetic operations along with 8-bit logic operations. The Boolean processor can handle operands from the special-function registers and 128 software flags in logical conditional branch and transfer operations. The Boolean processor has its own instruction set, its own accumulator (the carry flag), its own addressable RAM, and its own $\mathrm{I} / \mathrm{O}$.

The 8051 CPU manipulates operands in four memory spaces: 64-kbyte program memory, 64-kbyte external data memory, 16-bit program counter, and 384-byte internal data memory (256-byte internal data RAM and 128-byte special-function register). The internal data RAM contains four register banks of eight registers each, as well as the stack and 128 addressable bits.

The special-function registers are $1 / O$ mapped and include arithmetic registers, pointers, I/O ports, interrupt system registers, timers, and a serial port.

Addressing is flexible, and source operands are addressed five ways: register, direct, register indirect, immediate, and base register with index-register indirect.

The 8051 contains two 16-bit counters for measuring time intervals, counting events, measuring pulse widths, keeping time, and generating periodic interrupt requests. There are four programmable $1 / 0$ ports and one programmable serial port. The serial port is full duplex and can handle the standard asynchronous communication protocols.

There are five sources for interrupts: two via the external pins INT0 and INT1, one each from the two counter/timers, and one from the serial I/O port. There are two interrupt levels. Each vectored interrupt accesses a location in program memory for its service routine.

Intel plans to bring out a CMOS version (80C51) of this microcontroller in 1985. A 16-bit HMOS version (the 8096 family) is now available and possesses additional design features, the most important of which is operating speed.

The requirements for the conceived, enhanced heliostat microcomputer include the following:

- Approximately 12 kbytes ROM

- Approximately 400 bytes RAM

- A timer/counter for time of day

- A serial interface for the clock and mode-change inputs 
- Interrupt capability

- Boolean processing capability

- Three parallel I/O ports.

The 8051 can accomplish this with 8 kbytes of off-chip ROM (2732) and 1 kbyte of offchip RAM (8185A).

The Motorola MC68HC11A4 is a similar microcontroller chip that has M6801 compatibility and features 4 kbytes of on-chip ROM; 512 bytes of on-chip EEPROM; 256 bytes of on-chip RAM; a 16-bit timer; an 8-bit event counter; a serial, full-duplex communications interface; a serial peripheral interface; an 8-bit A/D converter; and four basic interrupt capabilities involving 21 interrupt vector assignments.

Although this CMOS chip was announced in 1983 , it will not be available until sometime in 1985 . 


\section{APPENDIX C}

\section{ADAPTIVE SELF-TUNING}

Self-tuning controllers can be used to regulate any industrial process. The design of most control systems involves four steps, namely, (1) derive a mathematical model that is based on the physical properties of the process, (2) identify the model parameters, (3) design the controller and establish its parameters, and (4) implement the controller. If disturbances that affect the system dynamics occur then the above steps must be repeated.

The increasing sophistication of microcomputers and declining purchase prices combined with digital control algorithms can lead to a controller that can skip the first two steps of the design process. An estimate of the process response time is required. The actual process output would be used as the input for the microprocessor controller, and the controller output would be the input for the process.

Given the precise time of day, a heliostat's microcomputer can compute its mirror vector to reflect sunlight directly onto the receiver. Error coefficients based on pedestal installation, drive misalignments, and mirror assembly are computed during calibration (see Appendix A) and then are used for compensation during the tracking mode. The error model does not cover unpredictable disturbances since they are stochastic in nature. A steady-on gusting wind, for example, will create a dynamic load on the heliostat's mirror assembly and will have a tendency to change the mirror vector. In such a case, an adaptive self-tuning controller would be appropriate. The calculated mirror vector that uses the error coefficients from the calibration process would serve as input to the adaptive controller. The adaptive controller uses information concerning the disturbance. A least-squares or maximum likelihood estimator for parameter identification and the minimum variance approach for a control strategy may be employed in the selftuning regulator to relate the controller coefficients to the identified model parameters. The response time of the controller may not be fast enough to handle "fast" wind gusts, but this would not be critical to the plant operation. 


\section{SELECTED DISTRIBUTION LIST}

Floyd Blake

Solar Energy Research Institute 1617 Cole Boulevard

Golden, CO 80401

Dr. Howard Coleman

U.S. Department of Energy

CE-314, Room 5H-021

Forrestal Building

1000 Independence Avenue, S.W.

Washington, D.C. 20585

Sigmund Gronich

U.S. Department of Energy

CE-314, Room 5H-021

Forrestal Building

1000 Independence Avenue, S.W.

Washington, D.C. 20585

John Holmes

Sandia National Laboratories

P. O. Box 5800

Albuquerque, NM 87115

Jim Leonard

Sandia National Laboratories

Division 6227

P. O. Box 5800

Albuquerque, NM 87115

Clay Mavis

Sandia National Laboratories

Division 8473

P. O. Box 969

Livermore, CA 94550
L. M. Murphy

Solar Energy Research Institute

1617 Cole Boulevard

Golden, CO 80401

Martin Scheve

U.S. Department of Energy

CE-314, Room 5H-041

Forrestal Building

1000 Independence Avenue, S.W.

Washington, D.C. 20585

Jack Swearingen

Sandia National Laboratories

Division 8453

P. O. Box 969

Livermore, CA 94550

John P. Thornton

Solar Energy Research Institute 1617 Cole Boulevard

Golden, CO 80401

Frank (Tex) Wilkins

U.S. Department of Energy

CE-314, Room 5H-041

Forrestal Building

1000 Independence Avenue, S.W.

Washington, D.C. 20585

Richard Wood

Solar Energy Research Institute 1617 Cole Boulevard

Golden, CO 80401 


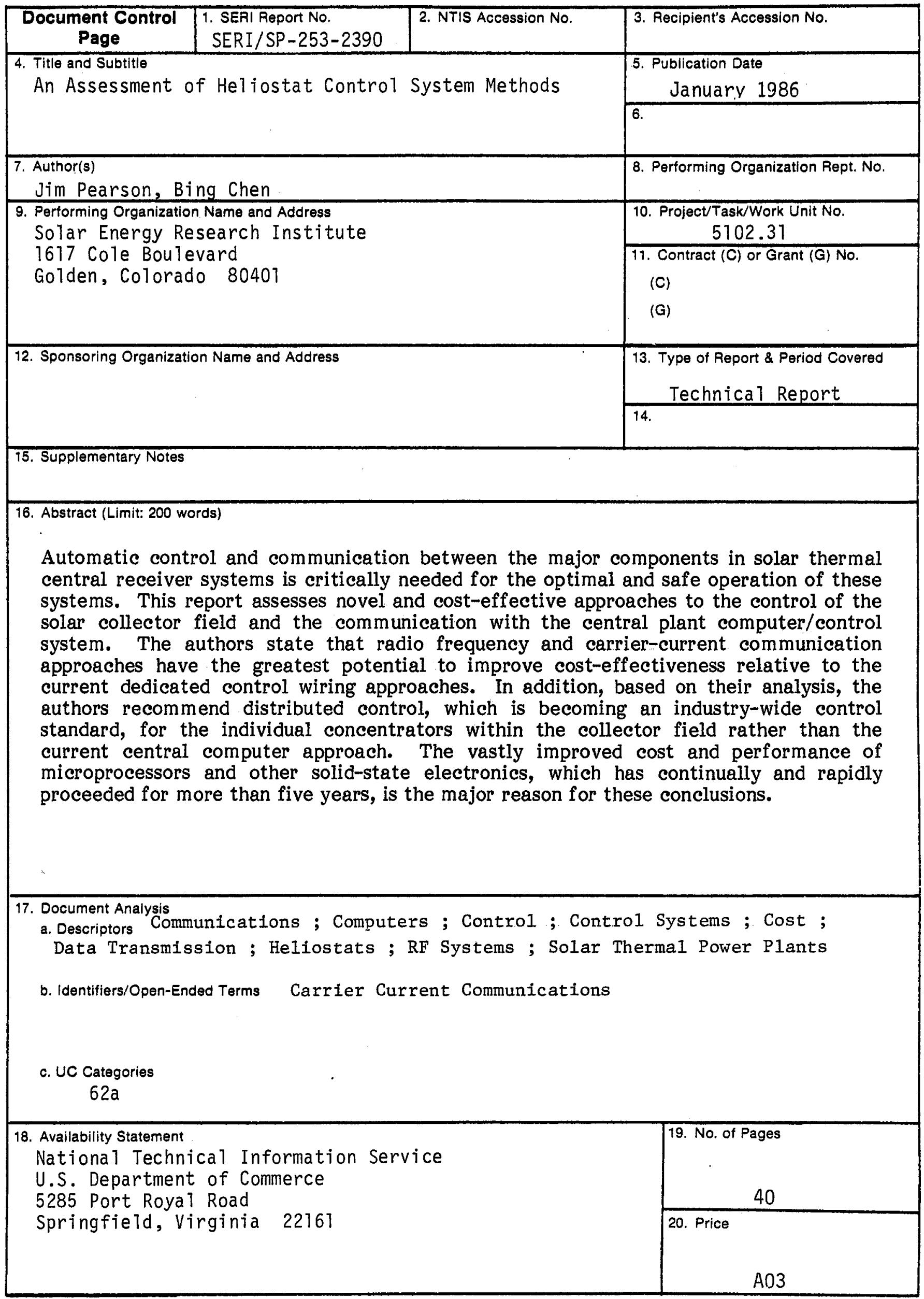

